\title{
Perencanaan Bumi Perkemahan Alun-Alun Suryakencana Taman Nasional Gunung Gede Pangrango, Jawa Barat
}

\author{
Imam Muttaqin ${ }^{1}$, Cokorda Gede Alit Semarajaya ${ }^{1 *}$, Lury Sevita Yusiana ${ }^{1}$
}

1. Program Studi Arsitektur Pertamanan, Fakultas Pertanian, Universitas Udayana, Indonesia 80114

*E-mail: coksemarajaya@unud.ac.id

\begin{abstract}
Camping ground planning of Alun-alun Suryakencana in Mt. Gede Pangrango National Park, West Java. A good campsite requires a plan. Planning is done zoning area that can be used as a camping area without disturbing the existing ecosystem and equipped facilities so that users can feel comfortable while in the area of the campground. Alun-alun Suryakencana at an altitude of $2750 \mathrm{~m}$ asl is part of the Mount Gede Pangrango National Park of West Java. This research was conducted in October 2016-August 2017, this research method refers to Rachman's (1984) complete thinking process in Norma (2013) which applies secondary data analysis at field study stage which consists of inventory, analysis, synthesis, concept, and planning. The final result of this planning is a Campsite Plan that is implemented in Alun-alun Suryakencana.
\end{abstract}

Keywords: alun-alun Suryakencana, camp ground, mt. Gede Pangrango national park

\section{Pendahuluan}

Taman Nasional Gunung Gede Pangrango (TNGGP) adalah taman nasional yang terletak di Provinsi Jawa Barat dengan luas $24.270,80 \mathrm{Ha}$, wilayahnya mencakup dua puncak gunung yaitu Gunung Gede 2.958 $\mathrm{m}$ dpl dan Gunung Pangrango $3.019 \mathrm{~m}$ dpl, beserta tutupan hutan pegunungan di sekelilingnya. Alun-alun Suryakencana merupakan bagian dari TNGGP berupa dataran seluas \pm 52 hektar yang ditutupi hamparan bunga edelweis (Anaphalis javanica). Berada pada ketinggian $2.750 \mathrm{~m}$ dpl, memiliki lahan yang nyaman bagi pendaki untuk bermalam dan mendirikan tenda di kawasan tersebut sebelum menuju ke puncak Gunung Gede.

Sesuai dengan salah satu fungsi taman nasional yaitu pariwisata dan rekreasi, TNGGP memberikan daya tarik wisata bagi pendaki maupun wisatawan yang berkunjung ke sana karena keindahan alamnya. Data statistik menunjukkan jumlah wisatawan yang berkunjung ke TNGGP pada tahun 2015 yaitu sebanyak 155.285 orang (Balai Besar TNGGP, 2015). Tingginya antusiasme wisatawan untuk melakukan wisata pendakian ke puncak Gunung Gede Pangrango menimbulkan permasalahan lingkungan di dalam kawasan TNGGP yang sebagian besar disebabkan oleh aktivitas pengunjung, baik pengunjung yang mendaki gunung, maupun yang berkemah.

Oleh karena itu, kawasan bumi perkemahan yang baik memerlukan sebuah perencanaan. Perencanaan tersebut dilakukan dengan menetapakan zonasi kawasan yang dapat digunakan sebagai kawasan berkemah tanpa mengganggu ekosistem yang ada dan merasa nyaman ketika berada di area bumi perkemahan.

2. Metode Penelitian

\subsection{Tempat dan Waktu Penelitian}

Lokasi penelitian dilakukan di Alun-alun Suryakencana berada pada ketinggian $2.750 \mathrm{~m}$ dpl yang merupakan bagian dari kawasan Taman Nasional Gunung Gede Pangrango. Taman Nasional Gunung Gede Pangrango berada di Cibodas, Kabupaten Cianjur, Jawa Barat. Waktu penelitian dilakukan pada bulan Oktober tahun 2016 sampai dengan bulan Juli 2017.

\subsection{Alat dan Bahan Penelitian}

Alat yang digunakan dalam penelitian ini meliputi kamera digital dan perangkat komputer dengan software Auto Cad dan Adobe Photoshop.

\subsection{Metode Penelitian}

Metode penelitian yang digunakan dalam penelitian ini mengacu pada metode proses berpikir lengkap Rachman (1984) dalam Norma (2013) yang menerapkan analisis data sekunder pada tahap studi lapangan yang terdiri dari tahap inventarisasi, analisis, sintesis, konsep, serta perencanaan. 


\subsubsection{Inventarisasi}

Tahap inventarisasi merupakan kegiatan pengumpulan data aspek biofisik dan aspek sosial. Data biofisik meliputi iklim, topografi, vegetasi, satwa, penggunaan lahan, dan kualitas visual. Data sosial meliputi data kondisi sosial, aktifitas, dan persepsi pengguna.

\subsubsection{Analisis}

Tahap analisis merupakan tahapan pengelolaan data yang telah diperoleh dari berbagai aspek sehingga diperoleh potensi dan kendala yang terdapat pada tapak.

\subsubsection{Sintesis}

Tahap sintesis merupakan suatu tahap pemanfaatan segala potensi dan berbagai upaya pemecahan masalah yang disesuaikan dengan tujuan penelitian. Berbagai potensi pada tapak diusahakan untuk dimanfaatkan dan dikembangkan, sementara kendala diminimalisir sehingga dapat mendukung pengembangan potensi agar mendapatkan konsep yang tepat dan sesuai.

\subsubsection{Konsep}

Tahap ini merupakan pengembangan ide berdasarkan potensi dan solusi masalah yang telah dilakukan pada tahap sintesis. Konsep dibagi menjadi konsep dasar dan konsep pengembangan. Konsep dasar merupakan konsep utama yang kemudian dikembangkan menjadi konsep pengembangan. Pada tahap konsep pengembangan akan menggambarkan konsep ruang, konsep sirkulasi dan konsep vegetasi.

\subsubsection{Perencanaan}

Perencanaan merupakan hasil yang dibuat berdasarkan analisis dan sintesis yang telah dilakukan dengan menghasilkan tata ruang, sirkulasi, dan tata hijau. Selanjutnya produk akhir yang dihasilkan dari konsep pengembangan yaitu berupa site plan tapak secara keseluruhan.

\section{Hasil dan Pembahasan}

\subsection{Inventarisasi Tapak}

\subsubsection{Aspek Biofisik}

Alun-alun Suryakencana merupakan bagian dari TNGGP berada pada zona pemanfaatan dan merupakan tanah terbuka pada peta zonasi dan tutupan lahan TNGGP. Alun-alun Suryakencana terbagi menjadi tiga bagian, yaitu Alun-alun Suryakencana barat, Alun-alun Suryakencana tengah, dan Alun-alun Suryakenca timur.

Sumber air pada tapak berasal dari mata air yang mengalir di Alun-alun Suryakencana barat. Air yang mengalir ini digunakan pendaki untuk air minum dan masak. Pola drainase pada tapak mengikuti topografi yang miring dari arah timur ke barat.

Ekosistem yang ada pada kawasan Alun-alun Suryakencana berada pada zona vegetasi Sub-Alpine, berada pada ketinggian di atas $2.400 \mathrm{~m}$ dpl. Kawasan Alun-alun Suryakencana didominasi oleh pohon-pohon pendek, antara lain Cantigi Gunung (Vaccinium varingiaefolium), dan terdapat jenis tumbuhan yang khas, yaitu Edelweis Jawa (Anaphalis javanica).

Aksesabilitas untuk menuju kawasan Alun-alun Suryakencana dapat ditempuh melalui tiga pintu masuk pendakian TNGGP yaitu melalui pintu masuk Cibodas, Gunung Putri, dan Salabintana.

\subsubsection{Aspek Sosial}

Menurut regulasi TNGGP kuota pendakian sebanyak 600 orang per hari, terbagi dari 300 orang melalui pintu masuk Cibodas, 200 orang melalui pintu masuk Gunung Putri dan 100 orang melalui pintu masuk Salabintana. Berdasarkan informasi yang diperoleh dari pengelola melalui wawancara, jumlah pengunjung mencapai puncaknya pada hari-hari libur nasional dan pada akhir pekan. Jumlah pengunjung terendah terjadi pada saat bulan puasa.

\subsection{Analisis dan Sintesis}

\subsubsection{Aspek Biofisik}

Alun-alun Suryakencana terletak di dalam wilayah zona pemanfaatan TNGGP. Luasnya \pm 52 hektar, dengan daya tampung maksimal 600 orang perharinya. Kawasan Alun-alun Suryakencana dapat didirikan \pm 150 tenda dengan ukuran tenda $2 \mathrm{~m} \times 2 \mathrm{~m}$, dimana satu tenda dengan ukuran tersebut dapat menampung 45 orang.

Kawasan Alun-alun Suryakencana memiliki tekstur tanah liat berpasir yang baik untuk penyerapan air hujan. Kondisi tanah yang cendrung datar dengan kemiringan 0-8\% menurut Hardjowigeno (1988) dalam 
Kusuma (2001) kesesuaian lahan untuk tempat berkemah termasuk katagori baik atau sudah memenuhi standar kelayakan sebagai kawasan yang nyaman bagi pendaki untuk mendirikan tenda di kawasan ini.

Adanya mata air yang mengalir di kawasan Alun-alun Suryakencana pengelola TNGGP memberikan aturan bagi pendaki yang berkemah di Alun-alun Suryakencana melalui Surat Keputusan Kepala Balai Besar Taman Nasional Gunung Gede Pangrango Nomor: SK. 84 /11-TU/1/2009 yang tertera pada Surat Izin Masuk Kawasan Konservasi (SIMAKSI) mengenai peraturan pendakian untuk tidak membawa detergen, odol, sabun mandi dan juga tidak membuang sampah atau sisa makanan di aliran sumber mata air bagi setiap pendaki supaya tidak mencemari air dan selalu terjaga kebersihannya.

Vegetasi dan satwa yang ada di Alun-alun Suryakencana memiliki potensi dan daya tarik bagi pengunjung sehingga perlu dijaga dan dilestarikan. Untuk itu, pendaki yang berkemah di Alun-alun Suryakencana agar selalu merawat dan menjaga ekosistem yang ada dengan tidak merusak dan memetik tanaman edelweis yang ada di kawasan Alun-alun Suryakencana, tidak membuang sampah atau sisa plastik makanan dan tidak melakukan kegiatan vandalisme lainnya di kawasan Alun-alun Suryakencana karena hal ini dapat merusak ekologi dan juga habitat atau ekosistem yang ada.

Aksesabilitas untuk menuju kawasan Alun-alun Suryakencana dapat ditempuh melalui tiga pintu masuk resmi pendakian TNGGP yaitu melalui pintu masuk Cibodas, Gunung Putri, dan Salabintana. Ketiga pintu masuk ini memiliki perbedaan jalur dan akses waktu tempuh yang beragam. Merujuk pada Purba (2008), aksesabilitas merupakan salah satu unsur penting yang dapat memberikan gambaran tentang sulit atau tidaknya suatu jalur pendakian. Penilaian jalur tersebut mengacu pada kondisi lereng, jarak tempuh, dan jenis permukaan jalur pendakian. Akses jalan yang selalu menanjak dan lebih cepat sampai ke Alun-alun Suryakencana dibandingkan dengan kedua jalur pendakian resmi lainnya, sehingga akses jalur Gunung Putri direkomendasikan bagi pendaki yang ingin langsung menuju Alun-alun Suryakencana.

\subsubsection{Aspek Sosial}

Tabel 1. Karakteristik Pengunjung

\begin{tabular}{|c|c|c|c|}
\hline No & $\begin{array}{l}\text { Karakter } \\
\text { Pengunjung }\end{array}$ & Analisis & Sintesis \\
\hline 1. & Jenis kelamin & $\begin{array}{l}\text { Laki-laki } 83,3 \%, \\
\text { sedangkan } \\
\text { perempuan } 16,7 \%\end{array}$ & $\begin{array}{l}\text { Hal ini disebabkan oleh sifat perempuan yang } \\
\text { lebih memilih jenis tempat pariwisata dengan } \\
\text { sanitasi yang baik dibandingkan laki-laki. Oleh } \\
\text { karena itu, pengelola diharapkan dapat } \\
\text { memberikan fasilitas sanitasi yang baik di } \\
\text { kawasan ini. }\end{array}$ \\
\hline 2. & Usia & $\begin{array}{l}66,7 \% \text { berusia } 17 \\
\text { sampai } 30 \text { tahun, } \\
\text { sekitar } 33,3 \% \text { berusia } \\
\text { diatas } 30 \text { tahun. }\end{array}$ & $\begin{array}{l}\text { Berdasarkan usia, dalam beraktivitas pada } \\
\text { umumnya pengunjung memiliki fisik dan stamina } \\
\text { yang masih prima. Untuk itu, pengunjung yang } \\
\text { akan melakukan pendakian, dan berkemah di } \\
\text { Alun-alun Suryakencana harus mempersiapkan } \\
\text { fisik dan stamina sebaik mungkin dengan } \\
\text { berolahraga rutin minimal seminggu sebelum } \\
\text { pendakian agar mengurangi resiko yang tidak } \\
\text { diinginkan. }\end{array}$ \\
\hline 3. & Asal & $\begin{array}{l}\text { 83,3\% berasal dari } \\
\text { daerah sekitar } \\
\text { Jabodetabek (Jakarta, } \\
\text { Bogor, Depok, } \\
\text { Tangerang, dan } \\
\text { Bekasi), 16,7\% dari } \\
\text { luar Jabodetabek }\end{array}$ & $\begin{array}{l}\text { Dominasi pengunjung berasal dari daerah sekitar } \\
\text { Jabodetabek karena jaraknya lebih dekat dengan } \\
\text { kawasan TNGGP. Sedikitnya jumlah pengunjung } \\
\text { yang berasal dari luar Jabodetabek disebabkan } \\
\text { karena jaraknya lebih jauh, sehingga pengunjung } \\
\text { perlu disediakan tempat perisitirahatan sementara } \\
\text { di sekitar kawasan TNGGP sebelum melakukan } \\
\text { pendakian. }\end{array}$ \\
\hline 4. & $\begin{array}{l}\text { Pendidikan dan } \\
\text { profesi }\end{array}$ & $\begin{array}{l}70 \% \text { S1, } 30 \% \text { SMA. } \\
60 \% \text { pelajar, } \quad 40 \% \\
\text { pegawai swasta, }\end{array}$ & $\begin{array}{l}\text { Banyaknya pengunjung dari golongan pelajar dan } \\
\text { mahasiswa menyebabkan kawasan ini ramai } \\
\text { pada akhir pekan dan pada saat liburan sekolah. }\end{array}$ \\
\hline
\end{tabular}


Lanjutan Tabel 1

\begin{tabular}{|c|c|c|c|}
\hline No & $\begin{array}{l}\text { Karakter } \\
\text { Pengunjung }\end{array}$ & Analisis & Sintesis \\
\hline & & & $\begin{array}{l}\text { Hal ini didukung juga lebih banyaknya waktu luang } \\
\text { mereka dibandingkan dengan waktu luang orang } \\
\text { dewasa yang sudah bekerja. Agar tidak terjadinya } \\
\text { jumlah pengunjung yang melebihi kapasitas daya } \\
\text { tampung kawasan, pengelola TNGGP } \\
\text { memberlakukan sistem ijin pendakian, yaitu } \\
\text { melalui pendaftaran maksimal satu hari sebelum } \\
\text { pendakian. Upaya yang dilakukan oleh pengelola } \\
\text { TNGGP sangat baik dan perlu dipertahankan } \\
\text { sebagai upaya untuk menjaga aktivitas pengguna } \\
\text { terhadap daya dukung kawasan. }\end{array}$ \\
\hline 5. & $\begin{array}{l}\text { Tujuan } \\
\text { pengunjung }\end{array}$ & $\begin{array}{l}90 \% \text { berkemah, } 10 \% \\
\text { penelitian. }\end{array}$ & $\begin{array}{l}\text { Banyaknya pengunjung yang datang bertujuan } \\
\text { untuk berkemah di kawasan ini sehingga perlu } \\
\text { dibuat perencanaan kawasan perkemahan yang } \\
\text { baik agar dapat mendukung aktivitas pengunjung } \\
\text { dan daya dukung kawasan. }\end{array}$ \\
\hline
\end{tabular}

\subsection{Konsep Dasar}

Konsep dasar dari bumi perkemahan Alun-alun Suryakencana yaitu bumi perkemahan yang ramah lingkungan dan bernuansa alam yang memperhatikan daya dukung ekologi. Untuk mewujudkan hal tersebut, maka dibuat suatu perencanaan bumi perkemahan yang berbasis pada daya dukung ekologi yang ada di kawasan Alun-alun Suryakencana sesuai dengan prinsip-prinsip pembangunan bumi perkemahan menurut Perlindungan Hutan dan Pelestarian Alam (1986) dalam Dewi (2012) untuk memenuhi fungsi konservasi sebagai berikut:

1. Layout bumi perkemahan harus seminimal mungkin mengubah alam lingkungan.

2. Penyebaran areal tidak terlalu luas agar dapat dikendalikan secara efektif.

3. Pembangunan dan pemanfaatannya tidak akan menimbulkan kerusakan atau menurunkan potensi ekosistem lingkungan.

4. Harus mampu memberikan perlindungan dan keamanan yang cukup terhadap areal bumi perkemahan.

5. Mempunyai fasilitas dan akomodasi yang memadai bagi kepuasan pengguna areal bumi perkemahan.

6. Mudah dikelola tanpa memerlukan biaya tinggi oleh pihak pengelola.

\subsection{Pengembangan Konsep}

Selanjutnya, konsep perencanaan Bumi Perkemahan Alun-alun Suryakencana dibagi menjadi beberapa konsep pengembangan yaitu konsep ruang, konsep sirkulasi dan konsep vegetasi.

Konsep tata ruang dikembangkan berdasarkan pembagian zonasi tapak menjadi tiga, yaitu zona konservasi, zona perkemahan, dan zona pelayanan. Konsep sirkulasi dikembangkan berdasarkan pola sirkulasi yang ada, berfungsi sebagai jalur penghubung antar ruang. Konsep vegetasi pada tapak ini berfungsi sebagai kawasan konservasi dengan mempertahankan vegetasi lokal yang ada pada tapak seperti cantigi gunung (Vaccinium varingiaefolium), dan edelweis jawa (Anaphalis javanica) tanpa introduksi vegetasi dari luar. Selain itu juga vegetasi yang ada pada kawasan ini dapat dijadikan sebagai penguat fungsi ruang, penguat aktivitas dan salah satu fasilitas yang dapat dinikmati oleh pengunjung.

\subsection{Perencanaan}

\subsubsection{Tata Ruang}

Tata ruang merupakan penataan zonasi tapak. Berdasarkan fungsinya, penataan ruang dibagi menjadi tiga yaitu zona konservasi, zona perkemahan, dan zona pelayanan. Zona konservasi merupakan hutan alami yang ada pada tapak berfungsi sebagai penyangga tapak untuk mencegah terjadinya erosi, menjaga sumber air (hidrologis) dan menjaga habitat satwa. Zona perkemahan merupakan pusat aktivitas para pengunjung yang akan bekemah dan di dalam tapak terletak pada Alun-alun Suryakencana barat. Zona pelayanan atau fasilitas yang dapat dinikmati oleh pengunjung berfungsi untuk mendukung aktivitas pengunjung untuk berkemah yaitu tersedianya air bersih yang ada pada tapak. Beberapa fasilitas yang dikembangkan dalam area Bumi Perkemahan Alun-alun Suryakencana yaitu disediakannya area perapian. Fungsi dari area perapian ini digunakan untuk memasak dan membuat api unggun skala kecil sebagai penghangat.

Area sanitasi dipilih di area yang cukup tertutup dari area perkemahan dan jauh dari sirkulasi jalan. Area ini juga harus mudah dijangkau dari area perkemahan, berada di Alun-alun Suryakencana Barat. Sistem toilet yang dipakai adalah menggunakan toilet alami, dengan sistem gali lubang sedalam $20 \mathrm{~cm}$. Tujuan 
penggalian lubang adalah untuk menghambat penyebaran organisme penyakit yang bisa disebabkan oleh manusia, hewan, atau aliran hujan (Gambar 1).

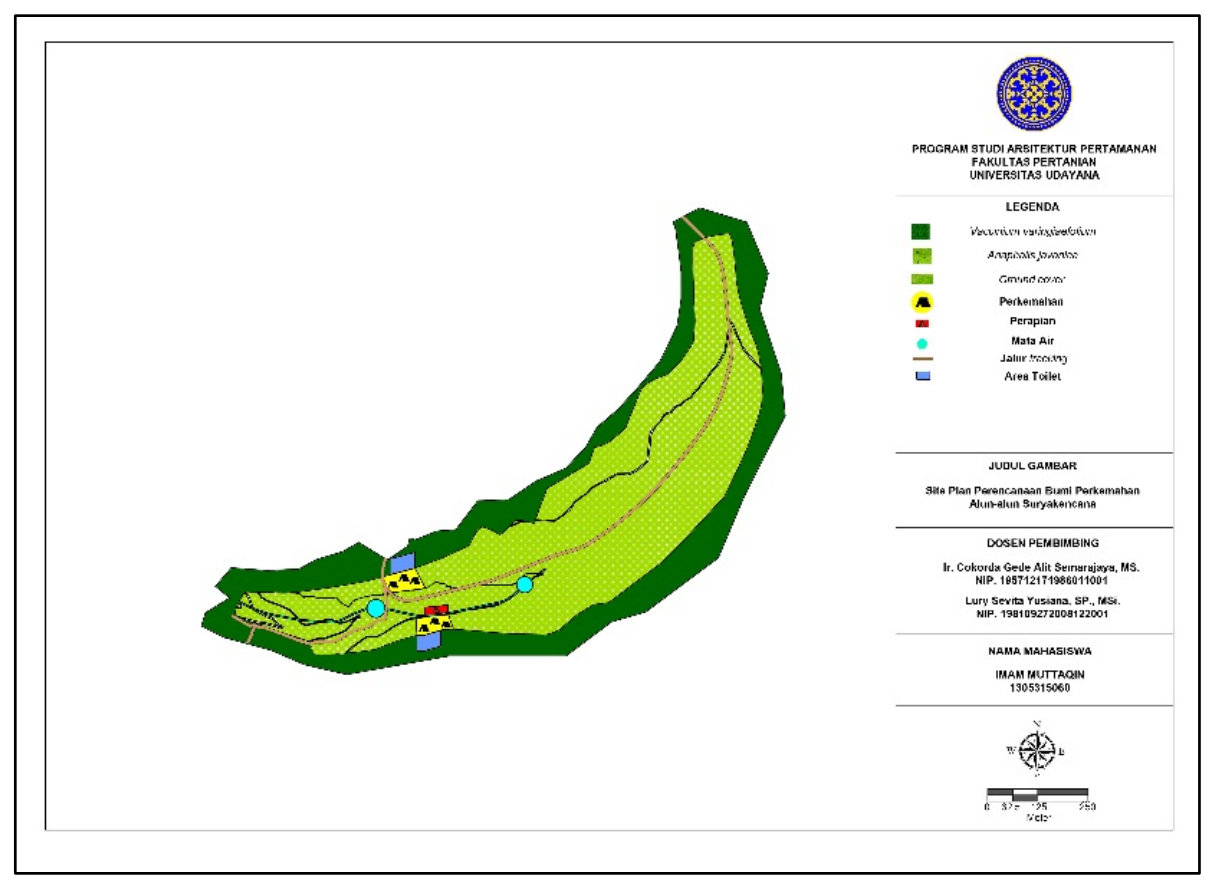

Gambar 1. Tata Ruang

\subsubsection{Sirkulasi}

Jalur sirkulasi yang direncanakan bertujuan untuk menghubungkan ruang-ruang dalam tapak dan mengakomodasikan berbagai aktivitas pengunjung. Pola sirkulasi yang diterapkan di kawasan ini menerapkan pola sirkulasi alami yang ada pada jalur lintasan bumi perkemahan yang digunakan pengunjung di dalam tapak untuk melewati dan menghubungkan antar ruang-ruang yang ada di dalam tapak (Gambar 2).

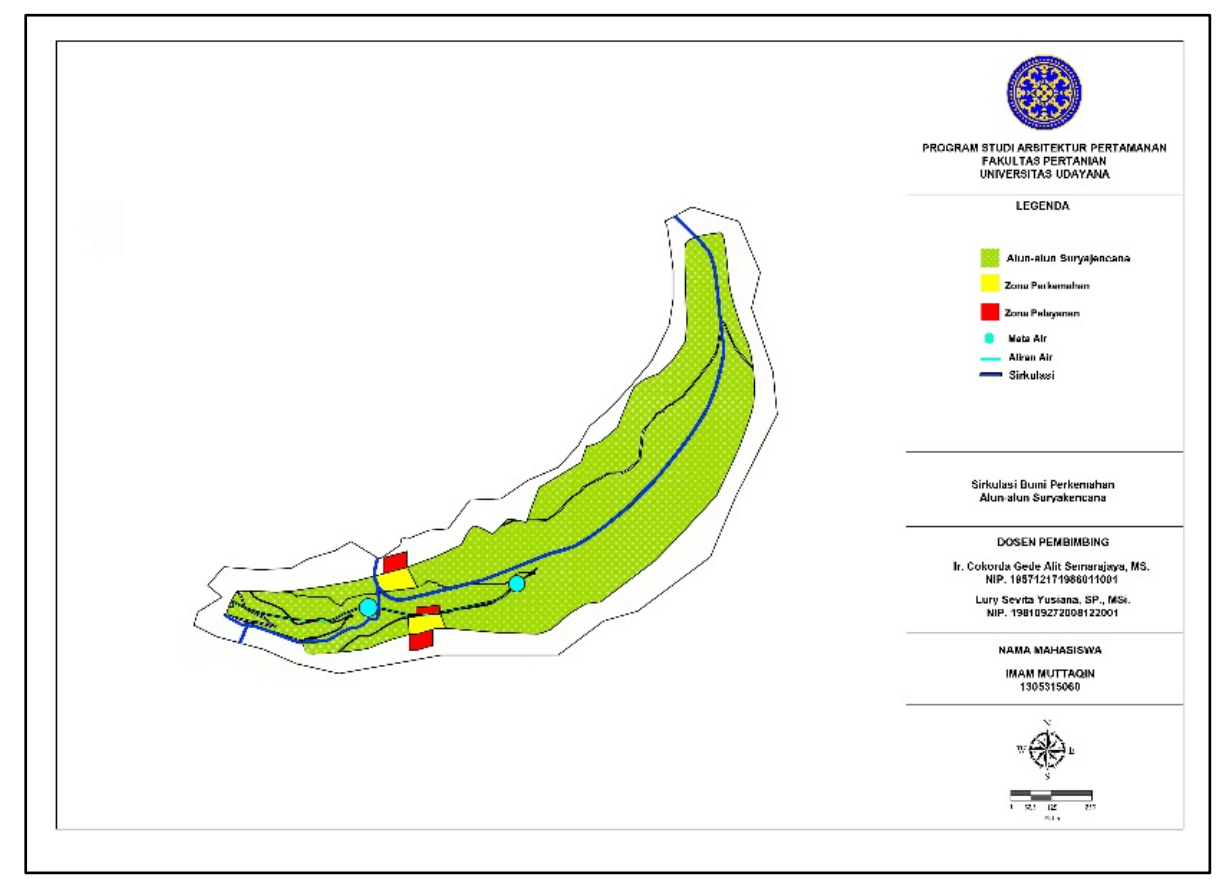

Gambar 2. Sirkulasi 


\subsubsection{Tata Hijau}

Tata hijau di area bumi perkemahan adalah memberikan kesan alami dan menjaga keseimbangan ekosistem yang ada pada tapak. Tata ruang dalam perencanaan Bumi Perkemahan Alun-alun Suryakencana memiliki fungsi hijau, diantaranya konservasi, penguat fungsi ruang, penguat aktivitas dan fasilitas (Gambar 3).

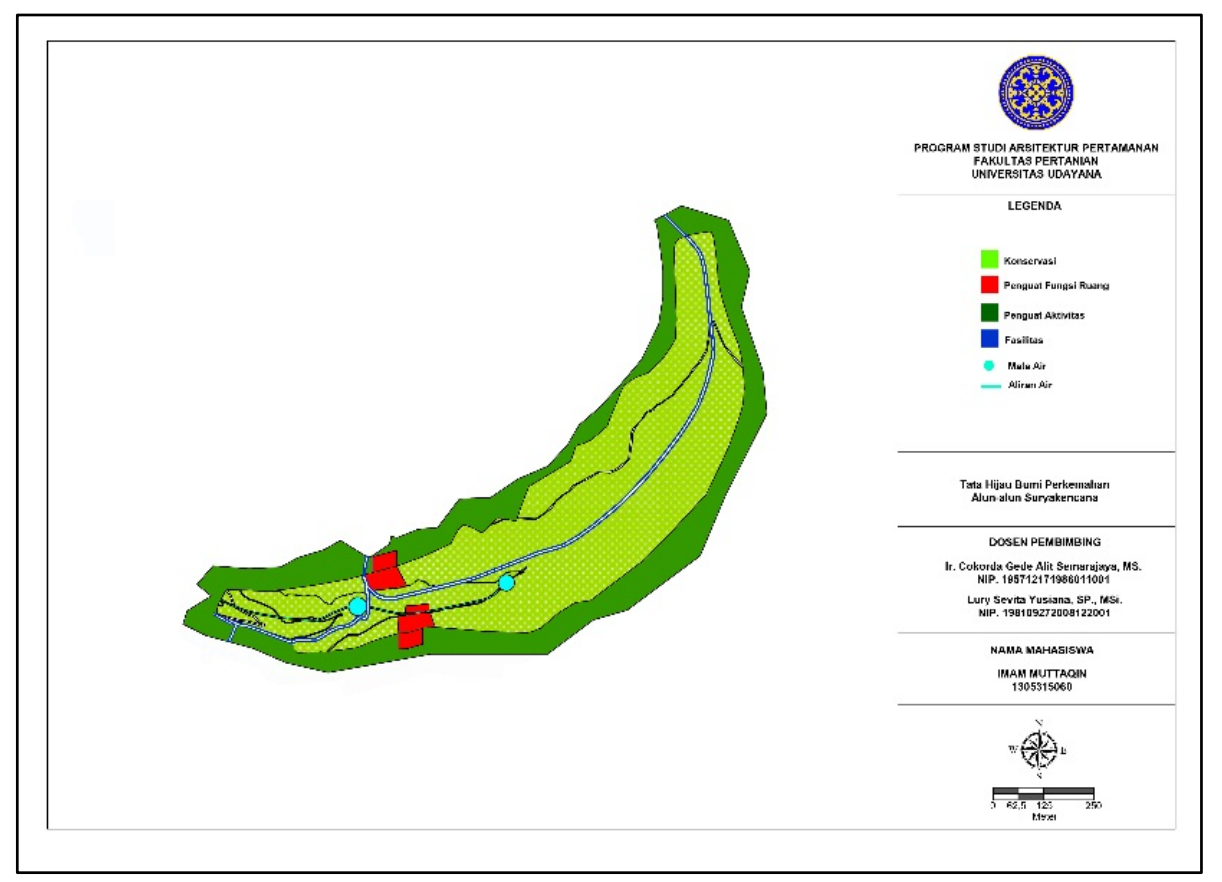

Gambar 3. Tata Hijau

Sehingga pada perencanaan ini terdapat produk akhir yang dihasilkan berupa site plan yaitu gambar final dari konsep pengembangan yang dapat dilihat pada (Gambar 4). 


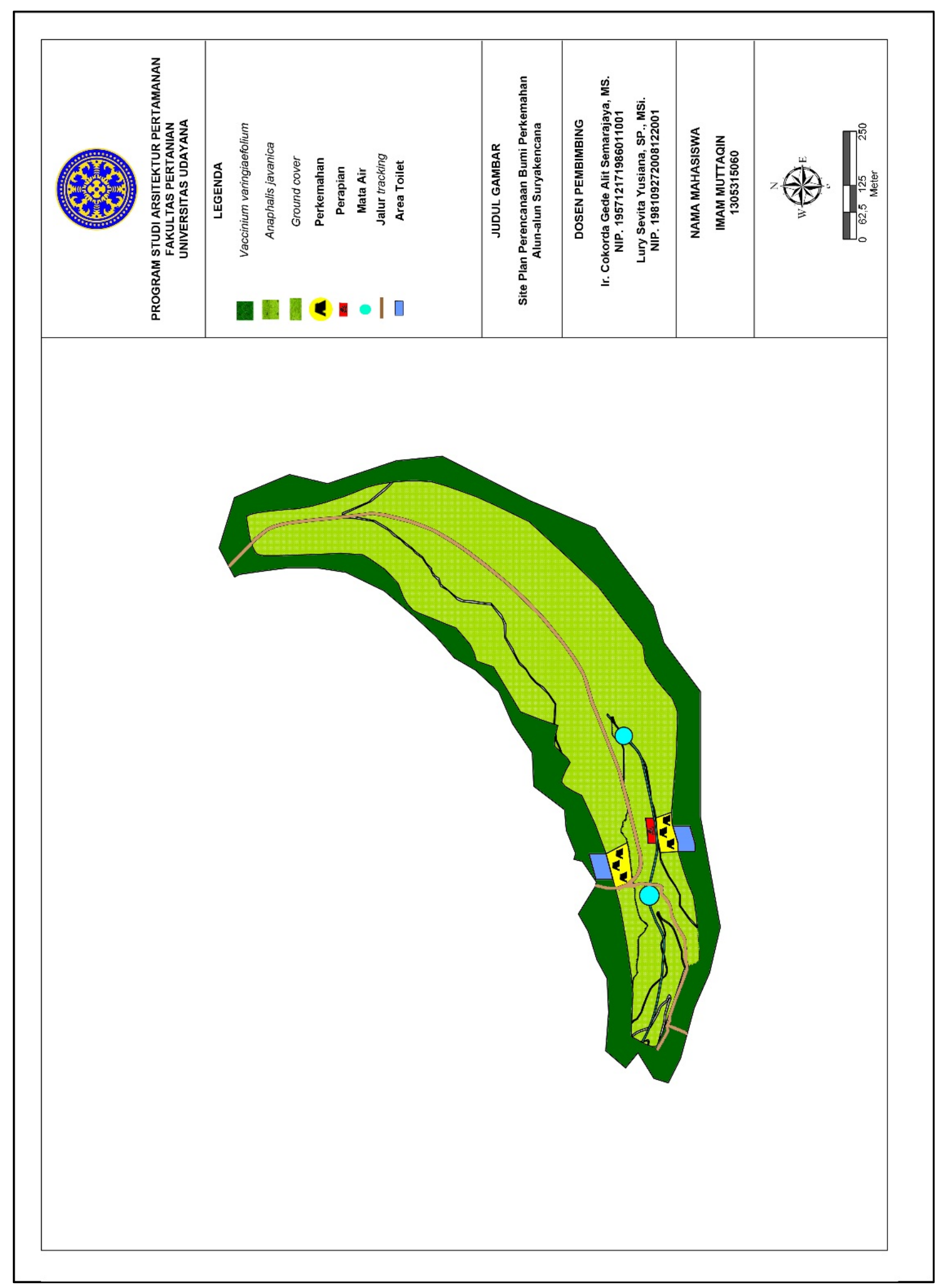

Gambar 4. Site Plan 


\section{Simpulan dan Saran}

4.1 Simpulan

1. Konsep dasar dari bumi perkemahan Alun-alun Suryakencana yaitu bumi perkemahan yang ramah lingkungan dan bernuansa alam yang memperhatikan daya dukung ekologi terhadap aktivitas pengguna.Tata ruang dikembangkan menjadi tiga, yaitu zona konservasi, zona perkemahan, dan zona pelayanan.

2. Fasilitas yang dikembangkan dalam area Bumi Perkemahan Alun-alun Suryakencana yaitu disediakannya area toilet yang letaknya berada di area yang cukup tertutup dari area perkemahan dan jauh dari sirkulasi jalan. Area ini juga harus mudah dijangkau dari area perkemahan.

3. Tata sirkulasi dikembangkan berdasarkan pola sirkulasi yang sudah ada, berfungsi sebagai jalur penghubung antar ruang. Pola sirkulasi yang diterapkan di kawasan ini menerapkan pola sirkulasi alami yang ada pada jalur lintasan bumi perkemahan di dalam tapak untuk dilewati dan menghubungkan antar ruang-ruang yang ada di dalam tapak.

4. Tata vegetasi pada tapak ini berfungsi sebagai kawasan konservasi dengan mempertahankan vegetasi yang ada pada tapak seperti cantigi gunung (Vaccinium varingiaefolium), dan edelweis jawa (Anaphalis javanica) tanpa introduksi vegetasi dari luar. Selain itu juga vegetasi yang ada pada kawasan ini dapat dijadikan sebagai penguat fungsi ruang, penguat aktivitas dan sebagai salah satu fasilitas yang dapat dinikmati oleh pengunjung.

5. Perencanaan Bumi Perkemahan Alun-alun Suryakencana merupakan hasil dari analisis dan sintesis, selanjutnya dibuat konsep pengembangan dengan hasil akhir berupa site plan.

\subsection{Saran}

Hasil perencanaan bumi perkemahan Alun-alun Suryakencana ini diharapkan dapat menjadi bahan masukan pengelola Taman Nasional Gunung Gede Pangrango untuk diaplikasikan di Alun-alun Suryakencana. Selanjutnya perencanaan ini dapat dikelola dan dikembangkan dengan baik sehingga tercipta suatu lanskap yang ramah terhadap lingkungan, dan ekosistem yang ada. Selain itu juga dapat memberikan rasa nyaman dan menyenangkan bagi penggunanya.

\section{Daftar Pustaka}

Selanjutnya hasil penelitian ini dapat digunakan sebagai salah satu sumber data untuk penelitian.

Balai Besar TNGGP. 2009. Keputusan Kepala Balai Besar Taman Nasional Gunung Gede Pangrango Nomor: SK. 84 /11-TU/1/2009 tentang Petunjuk Teknis Pelayanan Pendakian di Taman Nasional Gunung Gede Pangrango. Taman Nasional Gunung Gede Pangrango. Cianjur.

Balai Besar TNGGP. 2015. Statistik Balai Besar Taman Nasional Gunung Gede Pangrango. Taman Nasional Gunung Gede Pangrango. Cianjur. Tidak dipublikasikan.

Dewi, C.P. 2012. Kegiatan Proses Perancangan Lanskap untuk Pengembangan Wisata Alam di PT IdeA. Departemen Arsitektur Lanskap. Fakultas Pertanian. Institut Pertanian Bogor. Bogor.

Kusuma, E.L. 2001. Perencanaan Tapak Bumi Perkemahan Kawasan Wisata Alam Gunung Tujuh Taman Nasional Kerinci Seblat Kabupaten Kerinci, Jambi. Jurusan Budidaya Pertanian. Fakultas Pertanian. Institut Pertanian Bogor. Bogor.

Norma, M. P. 2013. Perencanaan Taman Terapi Hortikultura bagi Penderita Gangguan Jiwa pada Rumah Sakit Jiwa Provinsi Bali. Program Studi Arsitektur Pertamanan Jurusan Budidaya Pertanian Fakultas Pertanian Universitas Udayana.

Purba, E.J. 2008. Karakteristik Fisik Jalur Pendakian Gunung Gede. Skripsi. Fakultas Matematika dan IImu Pengetahuan Alam. Departemen Geografi. Universitas Indonesia. Depok. 